IRA-International Journal of Education \&

Multidisciplinary Studies

QUARTERLY

ISSN 2455-2526; Vol.16, Issue 04 (Oct.-Dec., 2020)

Pg. no. 253-258.

Institute of Research Advances

https://research-advances.org/index.php/IJEMS

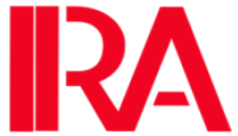

\title{
The New Teaching Model of the Integration of English Reading and Writing in High School
}

\author{
Wang Juan ${ }^{1 \#}$, Li Qing ${ }^{2}$, Li Xiaoxue ${ }^{3}$, Zhao Yuru ${ }^{4}$ \\ ${ }_{1,2,3.4}$ School of Foreign Languages, Yangtze University, China.
}

\#corresponding author

Type of Work: Peer-Reviewed

DOl: http://dx.doi.org/10.21013/jems.v16.n4.p7

\section{How to cite this paper:}

Wang Juan et al. (2020). The New Teaching Model of the Integration of English Reading and Writing in High School. IRA International Journal of Education and Multidisciplinary Studies (ISSN 2455-2526), 16(4), 253-258. DOl: http://dx.doi.org/10.21013/jems.v16.n4.p7

(C) Institute of Research Advances.

This work is licensed under a Creative Commons Attribution-NonCommercial 4.0 International License subject to a proper citation to the publication source of the work.

Disclaimer: The scholarly papers as reviewed and published by the Institute of Research Advances (IRA) are the views and opinions of their respective authors and are not the views or opinions of the IRA. The IRA disclaims of any harm or loss caused due to the published content to any party.

Institute of Research Advances is an institutional publisher member of Publishers International Linking Association Inc. (PILA-CrossRef), USA. The institute is an institutional signatory to the Budapest Open Access Initiative, Hungary advocating the open-access of scientific and scholarly knowledge. The Institute is a registered content provider under Open Access Initiative Protocol for Metadata Harvesting (OAI-PMH).

The journal is indexed \& included in WorldCat Discovery Service (USA), CrossRef Metadata Search (USA), WorldCat (USA), OCLC (USA), Open J-Gate (India), EZB (Germany) Scilit (Switzerland), Airiti (China), Bielefeld Academic Search Engine (BASE) of Bielefeld University, Germany, PKP Index of Simon Fraser University, Canada. 
IRA-International Journal of Education $\Xi^{\circ}$ Multidisciplinary Studies

\begin{abstract}
Reading and writing are two important parts of high school English teaching. Reading is the main way for students to input information, while writing is an important form of outputting information and a comprehensive reflection of students' English ability. Therefore, reading and writing content should be closely linked. However, in the practical teaching practice, teachers often separate reading teaching from writing teaching and fail to guide students to realize the complementary relationship between reading and writing, which often leads to low teaching performance and insignificant learning effects. Therefore, how to effectively integrate reading teaching and writing teaching in the teaching process of reading and writing training, promote writing by reading and lead reading by writing, is a difficult problem facing the majority of high school English teachers. The author found that the combination of class teaching in English reading and writing research can make the student constantly in the process of reading and the author dialogue, communication, and form their own understanding, for active information receiver and further become a have their own sense of readers, so as to do it in writing from time to tome words want to say, have words to say and have words to say, in the emotional attitude and method of writing has had the positive transformation, to improve the writing ability of certain. In addition, the case study of the integration of reading and writing has also improved teachers' professional cognition and teaching level. The first part of the paper introduces the current situation of English writing teaching in senior high school, the problems existing in students' writing, the necessity of combining reading with writing, and the purpose and significance of this study. The second part explains the importance of reading and writing and the ways to improve it through current research and literature review. The third part, through literature review, introduces the relevant research on the combination of reading and writing at home and abroad, and reveals the necessity of the integrated teaching of high school English reading and writing. The fourth part elaborates on the application of reading and writing integration in classroom teaching practice.
\end{abstract}

Keywords: New curriculum standard; High School English; the Integration of English Reading and Writing.

\title{
Preface
}

In the face of the serious disconnection between writing teaching and reading teaching in senior high school English teaching, which leads to the decline of students' English level, relevant education departments put forward the integrated teaching of reading and writing, which has improved senior high school English teaching to a certain extent. The new curriculum standard puts forward higher requirements for students' reading and writing ability. Reading pays more attention to the students' ability to understand the text. The examinee must read English materials quickly within a certain unit of time, and analyze, reason, and judge the materials. The composition type has been increased from one to two, which requires students to master not the form of language but the function of language and to have the ability of discourse 
instead of simple sentence output, which significantly improves the students' ability of flexible use of language. Reading is an important means of understanding language knowledge and collecting writing materials. Only through effective language input can students' language output be activated and expanded. Writing is a language output based on extensive reading, reasonable thinking, and personal cognitive level, and the two are inseparable. Curriculum highlights the conception of knowledge and ability to set the topic concept of the unity of conception, test contents include the broad scope, comprehensive strength, is examines the examinee to analyze information with knowledge and understanding of the reading ability of information, and examines the examinee to use knowledge to deal with information and expression ability in writing, to the examinee comprehensive language ability and innovation ability put forward higher request, in examines the examinee to language knowledge and language ability made unremitting exploration and hard work.

\section{Current situations and problems of English reading and writing teaching in senior high School}

As the second language of the majority of high school students in China, English is becoming more and more difficult to learn and the learning task is becoming heavier and heavier. Students' English learning in high school will have a great impact on their future exams and jobs. Therefore, it is necessary to optimize the teaching methods of high school English comprehensively. We should pay more attention to learning the basic knowledge of English. In the current high school English teaching, due to the wide range of English knowledge, students' overall command of English is often not satisfactory, especially in high school English reading and writing. At the same time, because there is no professional English teacher to provide professional reading and writing guidance, many students' English reading and writing ability has become a weak link, unable to fully apply the acquired English knowledge in daily reading and writing. Moreover, due to the ordinary high school class time and heavy task, writing training time, and wasted effort, in order to pursue the class schedule, many teachers in the teaching process only care about the interpretation of words and phrases, but ignore the teaching material arrangement in the writing task, causing students rarely get the teacher's classroom writing instruction, no effective mastery of the skills of writing, let alone to develop good writing habits. In order to cope with the examination, the written expression of the usual training form is also most simple. From the students' point of view, under the baton of exam-oriented education, they seldom have the opportunity to write in class due to the shortage of class hours. Due to the lack of classroom guidance from teachers, students have no concept of English writing, writing out of the composition is not clueless is a lot of language problems, as time passes will produce fear of difficulty, so as to give up writing learning. While teachers spend a lot of time and energy correcting students' compositions, many students only look at the marks, ignoring the mistakes and shortcomings pointed out, and make the same mistakes next time. Both teachers and students only pay attention to the result of writing, but ignore the process of writing; Teachers often grade from the perspective of content, vocabulary, and grammar while ignoring the importance of the text.

\section{The importance of reading and writing skills and ways to improve them}

(1) The importance of reading ability and ways to improve it 
In the process of high school English teaching, reading is an important part of, is also one of the main teaching tasks of English teachers, is to improve the students' overall English reading skills and the basis of daily English reading ability, people often say: "to the reader the college entrance examination", the content of the reading is not only a language discipline but also occupies the important position in English teaching. In view of a series of problems in senior high school English reading comprehension, teachers should provide students with professional teaching and guidance, let students carry out reading learning according to the requirements of the senior high School English reading syllabus, and make students develop good habits of daily English reading. In each English teaching class, a little time should be set aside for students to read In English, so as to develop students' ability to acquire information in reading, to convert information into their own language, and to express themselves according to their own ideas. Under the background of the new curriculum reform, in order to better improve the overall reading ability of high school students, it is necessary for students to read the reading materials given by teachers carefully. According to the relevant data, reading the text aloud keeps the brain in a very active state, which is conducive to memory. Silent reading, by contrast, is a state in which much of the brain's knowledge acquisition is dormant, and the school doesn't work as well. By reading aloud, students can greatly improve their understanding of English.

(2) The importance of writing ability and ways to improve it

The cultivation of writing level is the further improvement of senior high school students' basic English knowledge. English writing can effectively promote the internalization of language knowledge. In English class, after the teacher explains the words, grammar, and the main knowledge points of each unit in detail, students can write English articles with the help of appropriate teacher guidance and apply their knowledge to the understanding of English articles. In the process of writing, students use the relevant grammar, connect the words and phrases together, and then combine some related words to form an English article, so that students can have a deeper grasp of this knowledge. English writing has always been a weak link in English teaching. The main reason is that we have been using the writing habits of our mother tongue to express, and have not grasped the characteristics of English writing, so we must pay attention to the transformation of thinking. The improvement of writing ability is not overnight, but to step by step, continuous accumulation, especially to pay attention to reading comprehension, accumulation of materials in reading, knowledge internalization.

\section{The necessity of integration of High school English reading and writing}

Su Shi, a great literary master, once said: "Work in reading, and escape in writing", which profoundly reveals the dialectical relationship between reading and writing. In language teaching, reading is the input and writing is the output. The ability to read and write goes hand in hand. Only through a lot of reading input, is to have a native writing output. Therefore, the organic combination of reading teaching and writing teaching, the full play of the leading role of teachers and students, step by step, from easy to difficult, layer by layer in-depth, in order to consolidate students' reading ability on the basis of effectively improve their writing ability. Both the college Entrance Examination English reading and writing test candidates' 
comprehensive language skills, including the ability to obtain information, process information, analyze and solve problems in English, the ability to think and express in English, and the ability to communicate across cultures. The traditional teaching of reading and writing is seriously separated from each other, which not only fails to improve students' pragmatic ability but also restricts the development of students' thinking. It can be seen that the current English writing teaching in senior high schools should change the traditional mode of focusing only on the teaching of language knowledge and sentence level, and should improve students' comprehensive pragmatic ability through the teaching of reading and writing. Krashen, an American linguist, believes that the key to second language acquisition is to be exposed to a large amount of understandable information slightly higher than the level of learners themselves. He pointed out that in the non-native language environment, correct and idiomatic language output depends on sufficient and high-quality language input. If you want to improve your writing ability, you can't do without a lot of practice, but if you don't have a broad and effective reading foundation, you can't get in touch with native written language, and it's hard to write good articles. Thus it can be seen that the combination of reading and writing is the basic method of writing teaching.

\section{Application of high School English reading and writing integration}

In the comprehensive promotion of quality-oriented education today, how to make our teachers understand and apply the classroom teaching concept under the background of the new curriculum standards, through reading and writing strategies, organic combination of reading and writing, improve the writing ability of high school students, has become very urgent and necessary. In view of the current situation, only by truly combining reading and writing, by analyzing reading materials, can students understand the text structure and various styles of English articles, accumulate practical vocabulary and beautiful sentence patterns, and guide students to learn for use, can students' writing ability be greatly improved.

(1) Combined with reading teaching, strengthen the students' ability of layout.

An article is a collection of meaning-related sentences that are developed around a theme and combined together according to certain internal logical relations. Select a typical article or paragraph to guide and guide students to conduct an overall analysis of the reading materials, find out the theme of the article and the hierarchical relationship between each part, extract the meaning, structure and central idea of the article, make them familiar with the characteristics of various styles, improve the ability of comprehension. The following steps can be taken :(1) find out the topic sentence of each paragraph and the main idea of the paragraph;(2) On the basis of understanding the general idea of the paragraph, find out the topic of the article;(3) You can understand the structure of an article by identifying the main points of an argument. For example, the reading article in Using Language in 7-Unit One in pep edition is a recommendation letter. By guiding students to analyze the paper and find out the structure of the letter: Heading --greeting-- bodyWritten -- Signature. Then write the written article in this style so that students can follow the rules and regulations. The so-called "reading promotes writing", that is to read as a means, to write for the purpose let the students use the knowledge learned in reading to write training, to achieve the purpose of reading 
promotes writing. After analyzing and learning the reading text, the students can be guided to copy, abbreviate, rewrite, continue and expand the reading text.

(2) Use reading materials to enrich students' vocabulary knowledge.

Vocabulary is a weak spot of the student, so teachers should pay attention to in the process of English teaching for the interpretation of words to deepen the students' impression, especially focused on the differences between English and Chinese languages, such as the interpretation of verbs, prepositions, and word formation, and arrange more practice, English-Chinese translation, group sentence pattern exercises to strengthen the students' learning outcomes.

(3) Train students' writing thinking with the help of reading texts.

The college entrance examination questions are of various types, involving a wide range of aspects, including topics in students' daily life and study, as well as many social hot spots, which requires students to pay attention to observe, care about and understand social phenomena, and have a certain understanding of social problems. However, in practical writing, many students are unable to express themselves, have no personal thoughts, or know how to discuss and support their own views. They even have no way to start or even copy translation tips or hand in blank papers. Since the new curriculum reform, the texts in senior high school English textbooks have a wide range of topics and rich contents, including language, culture, customs, ethics, information, science, social focus issues and other contents. The characters, allusions and facts have provided a lot of materials for writing. In addition, the supporting synchronous newspapers and periodicals can also enable students to keep up with the trend of The Times and pay attention to the hot issues of social affairs. In daily reading teaching, teachers can ask students to discuss various typical topics encountered, and analyze which facts or examples can be used in which articles and how to express them. With a certain amount of accumulation, students in writing will not feel unable to write but will do something meaningful.

\section{Conclusion:}

To sum up, the application of the integrated teaching of reading and writing in senior High school English teaching conforms to the development requirements of quality-oriented education, which can effectively improve the English teaching level and promote the great progress of students' English ability. In the actual teaching, we can pay more attention to the integration of reading and writing, excavate teaching resources deeply, select materials rationally, cultivate students' comprehension ability, carry out continuous writing teaching, and implement the integrated teaching of English reading and writing in senior high school.

\section{References}

[1]. Cai Huiping. Fang Yan. (2006) A Survey and Analysis of the current situation of English writing teaching [J]. Foreign Language and Foreign Language Teaching, (9): 21-24. 
[2]. He Qun. (2012) Empirical Research on integrated Teaching of Reading and Writing in Senior High School English Teaching [D].Hunan Normal University.

[3]. Gao Qin. (2014) A Study on the Combination of English Reading and writing in High School [D]. Nanjing Normal University. 